\title{
Prediction of solar irradiance using grey wolf optimizer least square support vector machine
}

\author{
Zuhaila Mat Yasin ${ }^{1}$, Nur Ashida Salim ${ }^{2}$, Nur Fadilah Ab Aziz ${ }^{3}$, Hasmaini Mohamad ${ }^{4}$, \\ Norfishah Ab Wahab ${ }^{5}$ \\ 1,2,4,5 Faculty of Electrical Engineering, Universiti Teknologi MARA, Malaysia \\ ${ }^{3}$ Department of Electrical Engineering, College of Engineering, Universiti Tenaga Nasional, Malaysia
}

\begin{tabular}{|c|c|}
\hline Article Info & ABSTRACT \\
\hline Article history: & Prediction of solar irradiance is important for minimizing energy costs and \\
\hline Received Feb 20, 2019 & $\begin{array}{l}\text { providing high power quality in a photovoltaic (PV) system. This paper } \\
\text { proposes a new technique for prediction of hourly-ahead solar irradiance }\end{array}$ \\
\hline Revised May 17, 2019 & namely Grey Wolf Optimizer Least Square Support Vector Machine (GWO- \\
\hline Accepted Jul 11, 2019 & $\begin{array}{l}\text { LSSVM). Least Squares Support Vector Machine (LSSVM) has strong } \\
\text { ability to learn a complex nonlinear problems. In GWO-LSSVM, the }\end{array}$ \\
\hline Keywords: & $\begin{array}{l}\text { parameters of LSSVM are optimized using Grey Wolf Optimizer (GWO). } \\
\text { GWO algorithm is derived based on the hierarchy of leadership and the grey }\end{array}$ \\
\hline Grey wolf optimizer & wolf hunting mechanism in nature. The main step of the grey wolf hunting \\
\hline $\begin{array}{l}\text { Least-square support vector } \\
\text { machine }\end{array}$ & $\begin{array}{l}\text { mechanism are hunting, searching, encircling, and attacking the prey. The } \\
\text { model has four input vectors: time, relative humidity, wind speed and }\end{array}$ \\
\hline Particle swarm optimization & measure the prediction performance. Comparative study also carried out \\
\hline Photovoltaic & using LSSVM and Particle Swarm Optimizer-Least Square Support Vector \\
\hline Solar irradiation & $\begin{array}{l}\text { Machine (PSO-LSSVM). The results showed that GWO-LSSVM predicts } \\
\text { more accurate than other techniques. }\end{array}$ \\
\hline
\end{tabular}

Copyright $@ 2020$ Institute of Advanced Engineering and Science. All rights reserved.

\author{
Corresponding Author: \\ Zuhaila Mat Yasin, \\ Faculty of Electrical Engineering, \\ Universiti Teknologi MARA, \\ 40450, Shah Alam, Selangor, Malaysia. \\ Email: zuhailamy74@gmail.com
}

\section{INTRODUCTION}

Photovoltaic (PV) is a source of renewable energy that substitutes conventional fuel. The PV system and other renewable energy sources have recently developed and improved rapidly throughout the world due to environmental awareness and favorable political regulations from local governments (establishing feed-in tariffs designed to accelerate investment in renewable energy technologies) [1]. According to the European Photovoltaic Industry Association (EPIA), solar energy remains the third largest renewable energy source after hydro and wind power in terms of global installed capacity. In 2017, the newly installed photovoltaic energy capacity of at least 99.1 Gigawatts (GW) worldwide and the global cumulative installed capacity reached more than $400 \mathrm{GW}$ [2]. Due to the fast growth of PV installation, there is an increasing requirement for more exact and applicable modelling, prediction and forecasting of solar radiation since the output power induced in the PV modules is influenced by an intensity of solar irradiance [3, 4]. However, the complexity of the daily behavior of solar irradiation in terms of variability and non-stationary as well as its random characteristic, leads to consider more sophistical modelling and prediction techniques.

An accurate prediction of solar irradiance can reduce the impact of uncertainty of PV generation, improve the control algorithms of battery storage charge controllers and bring the significant cost benefit of the PV-storage systems [5]. Furthermore, the accurate prediction of solar irradiance is important in designing 
the control algorithm for Maximum Power Point Tracking (MPPT) [6, 7]. Artificial Neural Network (ANN) is one of the most famous predictive machine learning techniques [8-12]. The advantage of ANNs over other modelling techniques is the ability to model complex, nonlinear processes without assuming the form of the relationship between input and output variables. However, over fitting problems mostly occurs due to too many parameters to fix and fall into local minima [13]. The Support Vector Machine (SVM) model has been developed as an ANN over fitting solution. SVM's main idea is based on the concept of decision making plans that define decision limits [14]. To avoid local minima, SVM calculates universal optimal solutions. An improvement of the existing SVM algorithm is Least Squares-Support Vector Machine (LSSVM). LSSVM simplified the SVM process. In recent year, LSSVM models have seen an explosion of interest, and their applicability across a wide range of problem domains [15-18]. LSSVM models can be mainly used to solve problems related to prediction and classification. LSSVM is an enhancement of SVM. Modifications of SVM is based on the Statistical Learning Theory (SLT). The aim of LSSVM is to reduce the prediction error by iterative trials and errors. LSSVM applies square errors rather than negative errors in the cost function. LSSVM used equality constraint in function of formulation; meanwhile SVM used inequality constraint. In addition, LSSVM only compares linear equations to complicated applicants once. In terms of least quadratic, usage of QP increases data training complexity. At the same time, SVM led the kernel-based learning developments. The Karush-Kuhn-Tucker (KKT) system has been reformulated to solve the problem [19].

The accuracy of prediction in LSSVM depends on the selection of the kernel parameters. Therefore, this paper is proposed a new hybrid technique namely Grey Wolf Optimizer Least Square Support Vector Machine (GWO-LSSVM) to predict solar irradiation. From previous studies, it was found that GWO is one of the best alternatives for solving complex and large-scale optimization problems. Reference [20] has presented a maximum power point tracking (MPPT) design for a PV system using GWO technique. GWO overcomes the limitations such as lower tracking efficiency, steady-state oscillations, and transients as encountered in Perturb and Observe (P\&O) and improved Particle Swarm Optimization (IPSO) techniques. GWO technique was also implemented in [21] for solving economic dispatch problem with considering the valve-loading effects. The effectiveness of GWO was tested on 13-units system and TAIPOWER 40-units systems. Form the simulations results, it can be concluded that GWO offers promising and competitive results as compared to other methods. Another study was carried out in [22] for solving unit commitment problem with consideration of wind power generators along with thermal power system. It was found that GWO has the capability to obtain optimal results. In [23], GWO was utilized for determining multiple Distributed Generation (DG) location and sizing in a distribution system. The objective of the optimization were to minimize reactive power losses and improve the voltage profile of the distribution system, without violating power system constraints. The results showed that GWO performed better than Gravitational Search Algorithm (GSA) and the Bat Algorithm (BA) based meta-heuristic methods in terms of fitness and convergence time. The performance of GWO-LSSVM is compared to the performance of LSSVM and Particle Swarm Optimization-Least Square Support Vector Machine (PSO-LSSVM) [25] in terms of accuracy and convergence test.

\section{RESEARCH METHOD}

Historical data implemented in this paper were taken from National Renewable Energy (NREL)'s website. NREL are focusing on solving today's energy challenges. The data was taken during summer in 2017. The data was recorded every one hour which is hourly data on daylight. The inputs considered for prediction model were air temperature, relative humidity, wind speed and time. The output of the prediction model was set to solar irradiance. The number of training data is 692 data and the number of testing data is 173. The load behavior variations are due to weather conditions, different industrial activities etc. The amount of solar irradiance usually at a maximum of $12.00 \mathrm{p} . \mathrm{m}$ and $1.00 \mathrm{p} . \mathrm{m}$. The amount of solar irradiance per day is not consistent because of weather condition.

\subsection{Development of Least Square Support Vector Machine (LSSVM)}

In this paper, LSSVM method with radial basis function kernel is utilized to predict the solar irradiance. $X_{i}$ and $Y_{i}$ must be consider as input training data and output training data. It also be writen as $x_{k} \in R^{d}$ and $y_{k} \in R$. The multivariate function $f$ approximation has shown as training data in learning of LSSVM. The approximation showed the relationship between the input and the output. The function of LSSVM could be expressed as:

$$
F(x)=\omega^{\tau} \Phi(\mathrm{x})+\mathrm{b}
$$


The constant $b$ represents a scalar, while $\omega^{\tau}$ as the vector of m-dimensional. Hence, the function estimation of LSSVM could be expressed as:

$$
F(x)=\sum_{k=1}^{i} \alpha_{k} K\left(x, x_{k}\right)+b
$$

The following are popular kernel function $\left(x, x_{k}\right)$ used for LSSVM regression or classification problem:

i. Radial Basis Function (RBF)

$$
K\left(x, x_{k}\right)=\| \exp \left(-\left\|x-x_{k}\right\|^{2} / 2 \sigma^{2}\right.
$$

ii. Linear kernel

$$
K\left(x, x_{k}\right)=x^{\tau} x_{k}
$$

iii. Polynomial kernel with tuning parameter $\mathrm{c}$

$$
K\left(x, x_{k}\right)=\left(x^{\tau} x_{k} / c+1\right)
$$

The flowchart of LSSVM technique is presented in Figure 1. Once NREL's data has been collected, the data were arranged into input data and output data. Wind speed, relative humidity, air temperature, and time were selected as the input data. While, solar irradiance was selected as the output data. In this paper, $80 \%$ of the data were taken as the training data and $20 \%$ later as the testing data. After that, the initial tuning parameters are determined based on cross validation technique. This paper used RBF parameters which are gamma $(\delta)$ and sigma square $\left(\sigma^{2}\right)$. LSSVM will trains and calculates the error gradient.

Then, the rate of learning is estimated and the parameters values are updated. LSSVM runs continuously until the result meets the maximum function evaluation and the optimization has been successfully completed. Mean Absolute Percentage Error (MAPE) was used in this paper to measure the accuracy of the proposed prediction model. MAPE calculation is expressed as:

$$
M A P E=\left(\frac{1}{n} \sum_{i=1}^{n} \frac{\mid \text { Actual }_{i}-\text { Forecast }_{i} \mid}{\mid \text { Actual }_{i} \mid}\right) \times 100
$$

The number of testing data has represented as n, while Actual $_{i}$ and Forecast $_{i}$ are the actual output data and the predicted data of the LS-SVM.

\subsection{Development of Grey Wolf Optimizer - Least-Square Support Vector Machine (GWO-LSSVM)}

Grey Wolf Optimizer (GWO) is one of meta-heuristic algorithm proposed by Canis Lupus. The GWO algorithm has imitated the hierarchy of leadership and the grey wolf hunting mechanism in nature. Grey wolf have their own great organization that arranges them into role of position. The main step of the grey wolf hunting mechanism was to hunt, search for prey, encircle prey and attack prey [24]. The grey wolf have four stages, beginning with Alpha, Beta, Delta and Omega. Alpha act as a leader to all grey wolfs in the organization. Alpha is represented as decision making in the organization. Alpha is not necessarily the strongest grey wolf members, but the best in handling the pack. Beta is the subordinate wolf for Alpha. It will help Alpha to make a decision and organize additional package activities. Alpha will represent the best candidate. On the other hands, Delta is the lowest level in grey wolf organization. It also defines as scapegoat. Omega played an important role in the organization. The entire group will face internal struggles and problems if the Delta is lost. Lastly, Delta grey wolf is the second last grey wolf that place in the domination hierarchy of grey wolf. Delta needs to obey to Alpha and Beta but it was dominant to Omega. Delta also acts as hunters, elders, scouts, sentinels etc. Hence, GWO is modeled based on five steps which are social hierarchy, prey encircling, chasing, prey attacking and prey searching. In the social hierarchy, the fittest solution is Alpha, Beta, and Delta. While candidate solutions is Omega wolf, the optimization mechanism or define as hunting mechanism was guided by Alpha, Beta, Delta and followed by Omega. For encircling prey, the mathematical model's behavior has shown in (7) and (8):

$$
\overrightarrow{\mathrm{D}}=\left|\overrightarrow{\mathrm{C}} \cdot \overrightarrow{\mathrm{x}_{\mathrm{p}}}(\mathrm{t})-\overrightarrow{\mathrm{x}}(\mathrm{t})\right|
$$




$$
\overrightarrow{\mathrm{x}}_{(\mathrm{t}+1)}=\overrightarrow{\mathrm{x}_{\mathrm{p}}}(\mathrm{t})-\overrightarrow{\mathrm{A}} \cdot \overrightarrow{\mathrm{D}}
$$

The current iteration is defined as $\mathrm{t}, \vec{A}$ and $\vec{C}$ are coefficient vectors. These both vectors are calculated using (9) and (10). $\overrightarrow{\mathrm{x}_{\mathrm{p}}}$ is the prey position, and $\overrightarrow{\mathrm{x}}$ represents the grey wolf position [24].

$$
\begin{aligned}
& \vec{A}=2 \vec{a} \cdot \overrightarrow{r_{1}}-\vec{a}(\mathrm{t}) \\
& \vec{C}=2 \cdot \overrightarrow{r_{2}}
\end{aligned}
$$

For encircling step, position of grey wolf and prey were defined as $(X, Y)$ and $\left(X^{*}, Y^{*}\right)$. The position of grey wolf that involve in hunting activities need to be updated according to prey positions. For the hunting part, grey wolves must be able to recognize the place of the prey and surround it. This activity was conducted through Alpha. In an abstract research space, there is no idea of the location of the optimum (prey). In order to mathematically simulate the hunting behavior of grey wolves, the Alpha (best candidate solution), Beta and Delta must have a better knowledge of the potential location of the prey. The grey wolves end the hunt with the prey when it stops moving. For attacking step, movement of grey wolf approaching the prey is defined in terms of $\vec{a}$. The decrease values of $\vec{a}$ means that the grey wolfs start to approach the prey. If the value of $\mathrm{A}$ decreases below than $1(|\mathrm{~A}|<1)$, it will influence grey wolfs to attack the prey. If $\mathrm{A}$ value increases more than $1(\mathrm{~A} \mid>1)$, grey wolfs are forced to move away from the prey. Lastly, search process starts with the production of the grey wolfs' random population. The position of the prey is estimated over the course of iterations. To point out the exploration and exploitation, the parameter of $\vec{a}$ is reduced from 2 to 0 . After the candidate solution diverged $(\mid \overrightarrow{A \mid}>1)$ from the prey and converged $(\mid \overrightarrow{A \mid}<1)$, GWO algorithm will terminate. It means that the satisfaction of criterion was end. Figure 2 illustrates the overall flowchart of GWO-LSSVM.

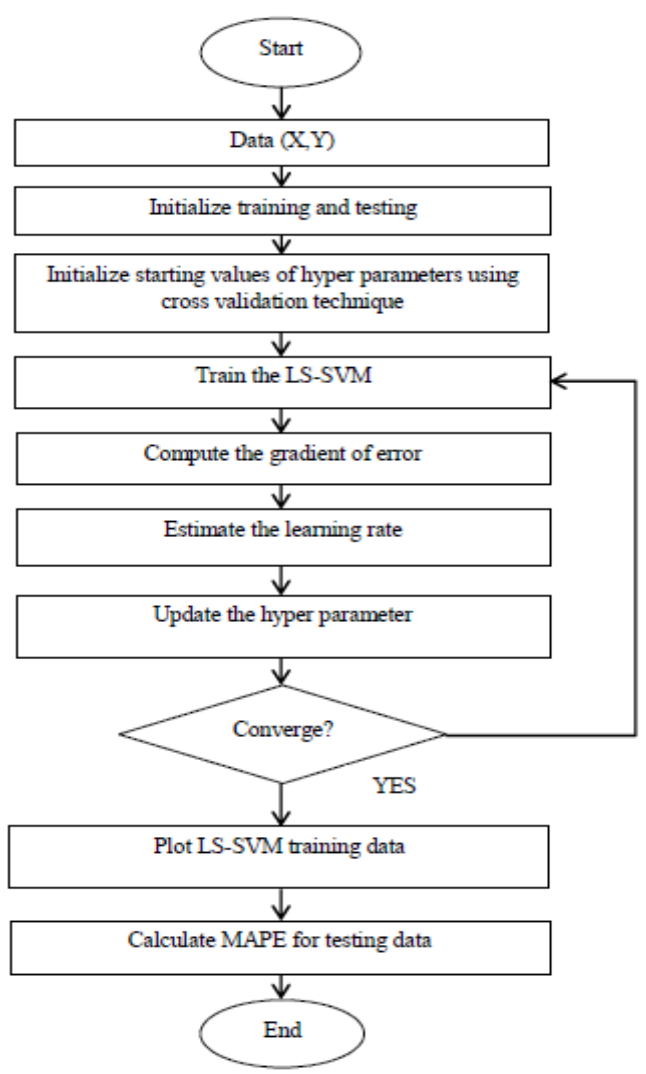

Figure 1. Flowchart of LSSVM

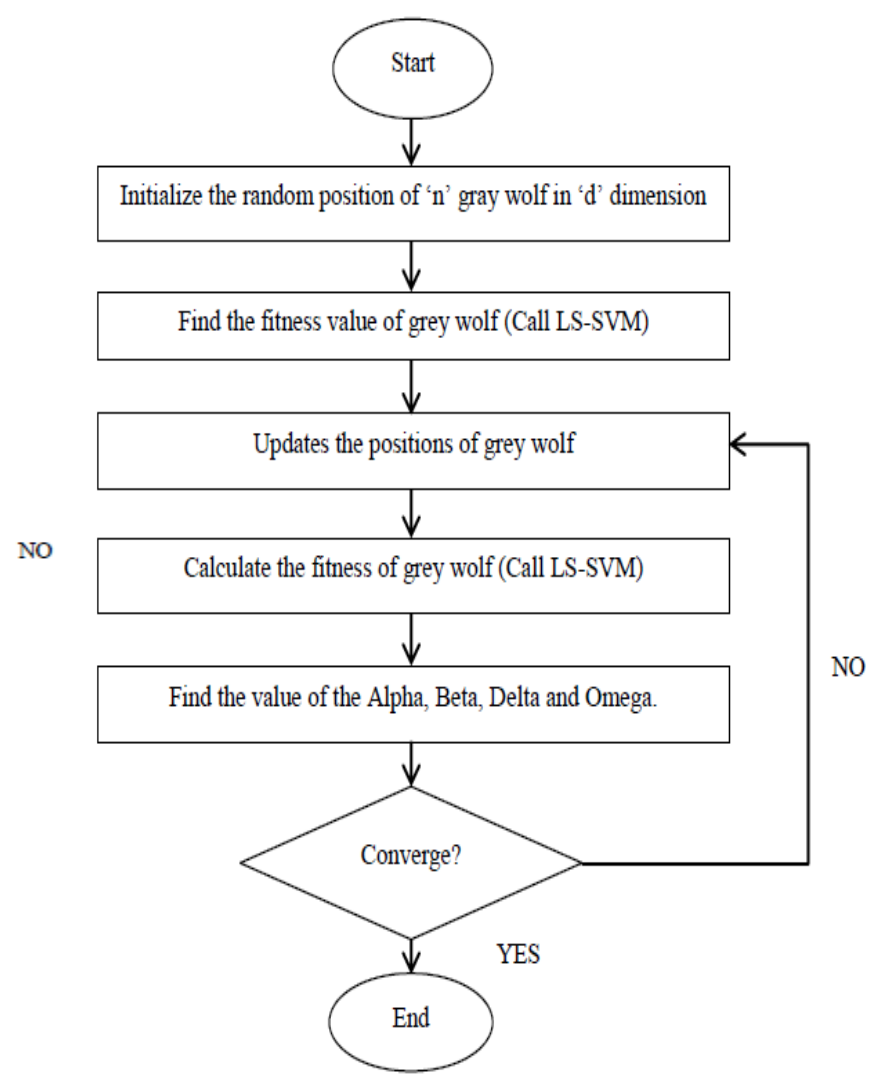

Figure 2. Flowchart of GWO-LSSVM 
Numbers of search agents are defined as packs of the wolf. In GWO program, the grey wolf types for social hierarchy are based on the number of dimensions in the GWO program. The number of dimensions is the number of variables considered this paper. The variables considered are gamma and sigma square. The search agents are initialized before the hunting step. Then, the grey wolf will encircle the prey. Search agents will update their position to others according to the positions of the prey. The location of the search agents depends on search agent number, dimension, and value of lower and upper bound that set in GWO program. Once the position has been initialized, the search agent converges to find the best search agent and develop the search agent's hierarchy. The program will continuously run until GWO converge or reach the maximum number of iteration. The number of iteration set in the program is 60 iterations.

\section{RESULTS AND DISCUSSIONS}

The historical data used in this paper were divided into two parts. $80 \%$ of the overall data were used for training. Meanwhile, 20\% amount of historical data were used for testing. Number of training data is 692 data and number of testing data is 173 . The results of LSSVM using cross validation technique for training and testing data are shown in Figure 3 and Figure 4. The predicted data $\left(Y_{t}\right)$ was shown in red colour, while the actual data was shown in blue colour. From Figure 3, it can be seen that the predicted and actual data has similar pattern. The values of gamma and sigma square that generated by LSSVM using cross validation technique were 9057.5126 and 25.6343 respectively. The MAPE value is $15.4908 \%$. In order to improve the solar irradiance prediction of LSSVM, GWO is hybridized to determine the optimal RBF parameters. The RBF parameters consist of gamma and sigma square. Figure 5 and Figure 6 present the training and testing results using GWO-LSSVM respectively.

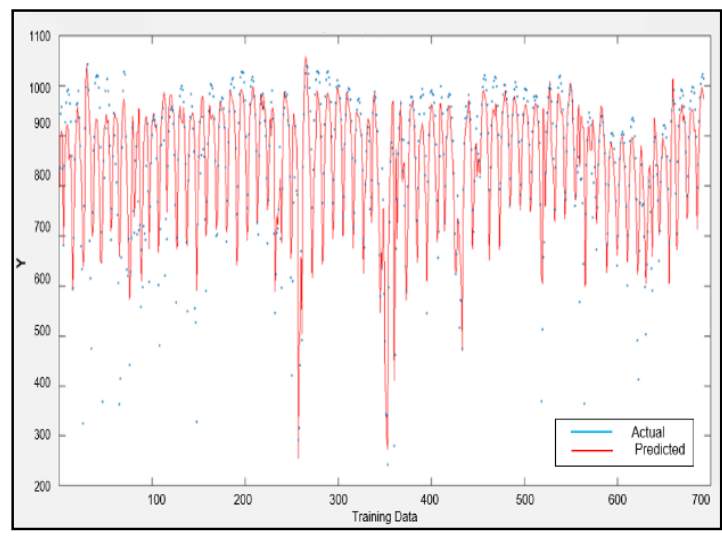

Figure 3. Results of training data using LSSVM

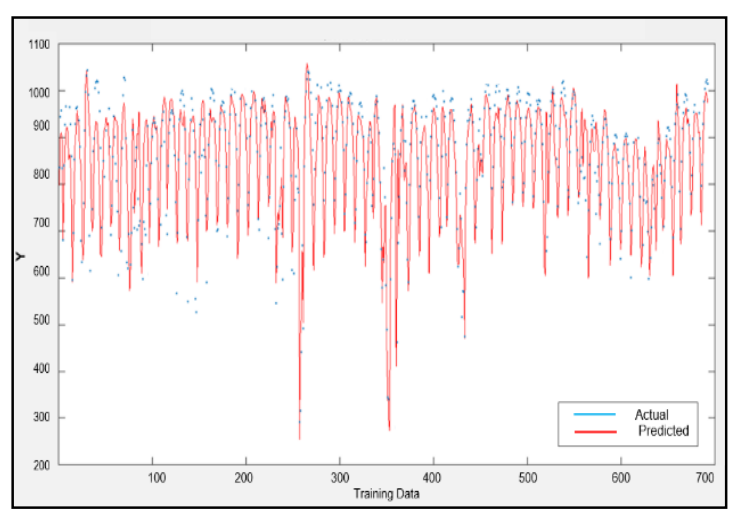

Figure 5. Results of training data using GWOLSSVM

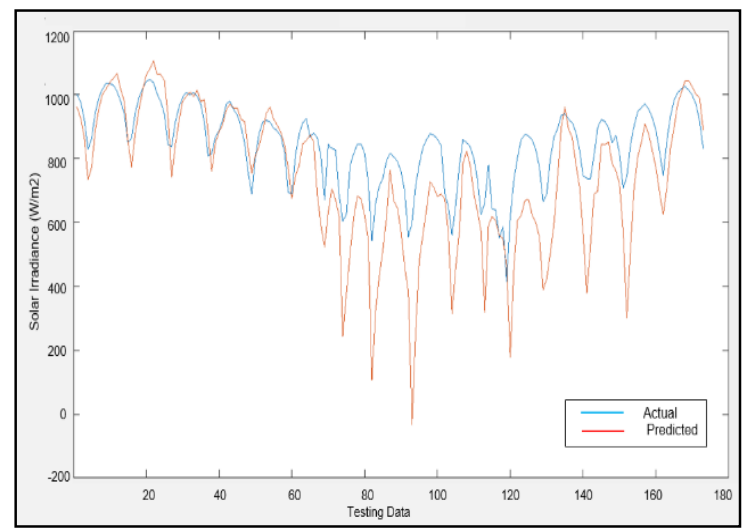

Figure 4. Results of testing data using LSSVM

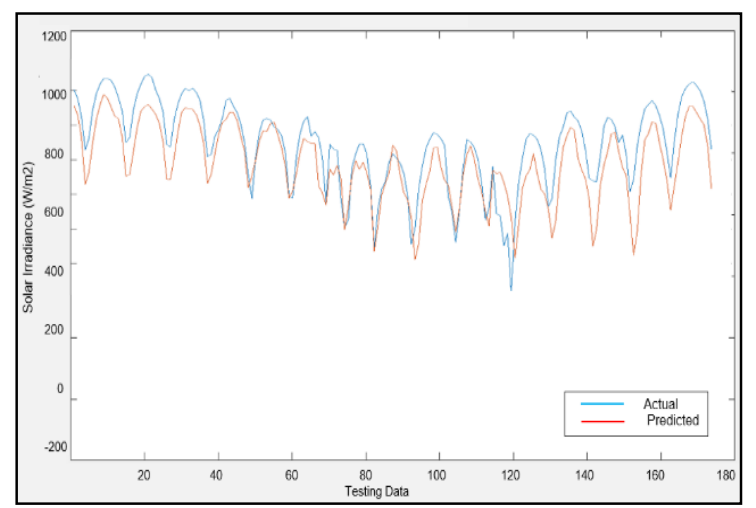

Figure 6. Results of testing data using GWOLSSVM 
From the results presented in Figure 5, it can be observed that the predicted data are slightly similar to the actual data. Similar observation can be seen in Figure 6 for testing data, where the predicted data has similar pattern with the actual data. The MAPE value is only $7.3167 \%$. By using GWO-LSSVM, the value of MAPE has reduced from $15.4908 \%$ to $7.3167 \%$. In GWO-LSSVM, the RBF parameters were optimally selected. Therefore, the prediction performance of GWO-LSSVM is better than LSSVM with crossvalidation technique. In order to verify the effectiveness of GWO-LSSVM, the results were also compared to PSO-LSSVM in terms of accuracy and convergence test. The number of maximum iteration and search agents that set for both techniques are same which are 60 maximum iteration and 20 search agents. Figure 7 shows the convergence results of GWO-LSSVM and PSO-LSSVM.

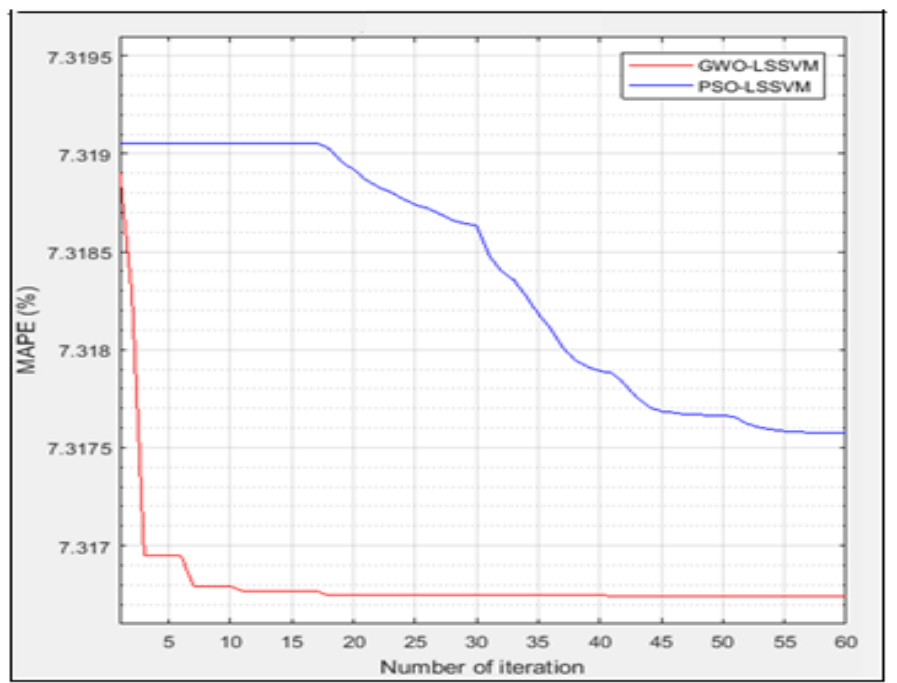

Figure 7. Convergence result of GWO-LSSVM and PSO-LSSVM

The results presented in Figure 7 shows that GWO-LSSVM produced the lowest value of forecasting error as compared to PSO-LSSVM. The value of MAPE for GWO-LSSVM was 7.3167\%, meanwhile PSO-LSSVM was 7.3176\%. Furthermore, GWO-LSSVM has faster convergence rate than PSOLSSVM. GWO-LSSVM converged at 18th iteration, while PSO-LSSVM converged at 57th. From this study, it can be concluded that GWO-LSSVM can predict the solar irradiance more accurate than PSOLSSVM and LSSVM.

\section{CONCLUSION}

This paper had presented a new technique to forecast solar irradiance namely Grey Wolf Optimizer Least Square Support Vector Machine (GWO-LSSVM). In GWO-LSSVM, the parameters of LSSVM were optimized using Grey Wolf Optimizer (GWO). GWO has imitated the hierarchy of leadership and the grey wolf hunting mechanism in nature. There are five steps of hunting mechanism of grey wolf which are it social hierarchy, prey encircling, chasing, prey attacking and prey searching. The hourly data on daylight was utilized as the input to LSSVM for prediction of solar irradiance. The inputs considered for prediction model were air temperature, relative humidity, wind speed and time. Meanwhile, the output of the prediction model was set to solar irradiance. The results indicated that the proposed technique provide better prediction performance as compared to other techniques such as LSSVM and Particle Swarm Optimization -Least Square Support Vector Machine (PSO-LSSVM).

\section{ACKNOWLEDGEMENTS}

The authors would like to thank the Research Management Institute (RMI), Universiti Teknologi MARA, Malaysia and the Ministry of Higher Education (MOHE), Malaysia through research grant 600IRMI/FRGS 5/3 (157/2019) for the financial support of this research. 


\section{REFERENCES}

[1] S. Kouro, J. I. Leon, D. Vinnikov, and L. G. Franquelo, "Grid-connected photovoltaic systems: An overview of recent research and emerging PV converter technology," IEEE Industrial Electronics Magazine, 2015.

[2] SolarPower Europe, "Global Market Outlook for Solar Power 2017-2021,” 2017.

[3] A. Attou, A. Massoum, and M. Saidi, "Photovoltaic power control using MPPT and Boost converter," Balkan journal of Electrical \& Computer Engineering, 2014.

[4] S. Pelland, J. Remund, J. Kleissl, T. Oozeki, and K. De Brabandere, "Photovoltaic and Solar Forecasting: State of the Art," International Energy Agency: Photovoltaic Power Systems Programme, Report IEA PVPS T14, 2013.

[5] X. Qing and Y. Niu, "Hourly day-ahead solar irradiance prediction using weather forecasts by LSTM," Energy, 2018.

[6] A. A. Abdulrazzaq and A. Hussein Ali, "Efficiency Performances of Two MPPT Algorithms for PV System With Different Solar Panels Irradiancess," International Journal of Power Electronics and Drive Systems (IJPEDS), 2019.

[7] M. Yaichi, M. K. Fellah, and A. Mammeri, "A neural network based MPPT technique controller for photovoltaic pumping system," International Journal of Power Electronics and Drive Systems(IJPEDS), 2014.

[8] F. Salem and M. A. Awadallah, "Detection and assessment of partial shading in photovoltaic arrays," Journal of Electrical Systems and Information Technology, 2016.

[9] W. Chine, A. Mellit, V. Lughi, A. Malek, G. Sulligoi, and A. Massi Pavan, "A novel fault diagnosis technique for photovoltaic systems based on artificial neural networks," Renewable Energy, 2016.

[10] Y. Sun, S. Li, B. Lin, X. Fu, M. Ramezani, and I. Jaithwa, "Artificial Neural Network for Control and Grid Integration of Residential Solar Photovoltaic Systems," IEEE Transactions on Sustainable Energy, 2017.

[11] V. Sharma, D. Yang, W. Walsh, and T. Reindl, "Short term solar irradiance forecasting using a mixed wavelet neural network," Renewable Energy, vol. 90, pp. 481-492, 2016.

[12] N. Roy and K. Bhattacharya, "Detection, classification, and estimation of fault location on an overhead transmission line using s-transform and neural network," Electric Power Components and Systems, vol. 43, no. 4, pp. 461-472, 2015.

[13] S. K. H. Chow, E. W. M. Lee, and D. H. W. Li, "Short-term prediction of photovoltaic energy generation by intelligent approach," Energy and Buildings, vol. 55, pp. 660-667, 2012.

[14] W. H. Chen, J. Y. Shih, and S. Wu, "Comparison of support-vector machines and back propagation neural networks in forecasting the six major Asian stock markets," International Journal of Electronic Finance, vol. 1, no. 1, p. 49, 2006.

[15] X. Yan, Y. Song, and N. A. Chowdhury, "Performance evaluation of single SVM and LSSVM based forecasting models using price zones analysis," in Asia-Pacific Power and Energy Engineering Conference, APPEEC, 2016, vol. 2016-Decem, pp. 79-83.

[16] S. Ismail, A. Shabri, and R. Samsudin, "A hybrid model of self-organizing maps (SOM) and least square support vector machine (LSSVM) for time-series forecasting," Expert Systems with Applications, vol. 38, no. 8, pp. 1057410578, 2011.

[17] A. Zendehboudi, "Implementation of GA-LSSVM modelling approach for estimating the performance of solid desiccant wheels," Energy Conversion and Management, vol. 127, no. 11, pp. 245-255, 2016.

[18] Y. Gao, S. Liu, F. Li, and Z. Liu, "Fault detection and diagnosis method for cooling dehumidifier based on LSSVM NARX model," International Journal of Refrigeration, vol. 61, pp. 69-81, 2016.

[19] S. M. Abd Elazim and E. S. Ali, "Optimal Power System Stabilizers design via Cuckoo Search algorithm," International Journal of Electrical Power \& Energy Systems, vol. 75, pp. 99-107, 2016.

[20] S. Mohanty, B. Subudhi, and P. K. Ray, "A new MPPT design using grey Wolf optimization technique for photovoltaic system under partial shading conditions," IEEE Transactions on Sustainable Energy, vol. 7, no. 1, pp. 181-188, 2016.

[21] M. H. Sulaiman, W. Lo Ing, Z. Mustaffa, and M. R. Mohamed, "Grey wolf optimizer for solving economic dispatch problem with valve-loading effects," ARPN Journal of Engineering and Applied Sciences, vol. 10, no. 21, pp. 9796-9801, 2015.

[22] S. S. Sakthi, R. K. Santhi, N. Murali Krishnan, S. Ganesan, and S. Subramanian, "Wind Integrated Thermal Unit Commitment Solution Using Grey Wolf Optimizer," International Journal of Electrical and Computer Engineering (IJECE), 2017.

[23] U. Sultana, A. B. Khairuddin, A. S. Mokhtar, N. Zareen, and B. Sultana, "Grey wolf optimizer based placement and sizing of multiple distributed generation in the distribution system," Energy, 2016.

[24] S. Mirjalili, S. M. Mirjalili, and A. Lewis, "Grey Wolf Optimizer," Advances in Engineering Software, vol. 69, pp. 46-61, 2014.

[25] R. Gholgheysari Gorjaei, R. Songolzadeh, M. Torkaman, M. Safari, and G. Zargar, "A novel PSO-LSSVM model for predicting liquid rate of two phase flow through wellhead chokes," Journal of Natural Gas Science and Engineering, 2015. 


\section{BIOGRAPHIES OF AUTHORS}
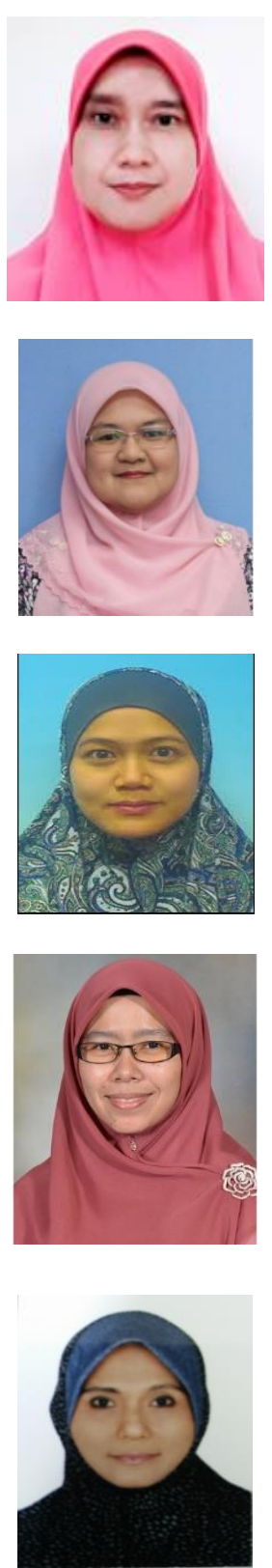

Zuhaila Mat Yasin graduated from Universiti Sains Malaysia with honours degree in Electrical and Electronics Engineering in 1998. She obtained her MSc degree in 2008 and PhD degree in 2015 from Universiti Teknologi MARA. She is currently a senior lecturer at Universiti Teknologi MARA, MALAYSIA. Her research interest includes power system operation, optimization, distributed generation, Artificial Intelligence and smart grid system.

Nur Ashida Salim received her Ph.D in Electrical Engineering from Universiti Teknologi MARA Malaysia in 2015 and MEng (Power System \& Electrical Energy) from Universiti Malaya in 2006. She is currently a lecturer at Universiti Teknologi MARA, MALAYSIA. Her research interests includes power system reliability, power system planning, power system stability and power system risk assessment.

Nur Fadilah Ab Aziz received her Ph.D in Electrical Engineering from Universiti Teknologi MARA Malaysia in 2014 and M.Eng. (Hons.) in Electrical Engineering from University of Southampton, in 2006. She is currently a senior lecturer at Universiti Tenaga Nasional (UNITEN) MALAYSIA. Her research interests includes power system planning, power system stability and Artificial Intelligent (AI) application in power system.

Hasmaini Mohamad received the B.Eng, M.Eng and Ph.D. degrees from the University of Malaya, in 1999, 2004, and 2013, respectively. She started her career as a lecturer in UiTM in 2003 where currently she is a senior lecturer. Apart from that, she has published more than 30 journal papers including high impact ISI journals and 20 conference papers. Her major research interest includes islanding operation of distributed generation, hydro generation, load sharing technique, and load shedding scheme.

Norfishah Ab Wahab was born in Malaysia, in 1963. She received the degree in electronics Engineering from Universiti Teknologi MARA (UiTM), Malaysia, MSc in Telecommunication and Information Engineering and $\mathrm{PhD}$ in microwaves, electromagnetism in the same university. Currently, she is a senior lecturer in Faculty of Electrical Engineering, UiTM Shah Alam, Malaysia. She has been working in UiTM since April 2008. From 1992 to 2004, she was employed by Telekom Malaysia. She worked in various divisions such as microwave, fiber cable and network system departments. Her major research areas are in microwave and electromagnetic modeling, low-powered electronic design, energy harvesting and efficiency. 